No. 09-6

\title{
The Optimal Level of Deposit Insurance Coverage
}

\section{Michael Manz}

\begin{abstract}
:
This paper develops a global game model that allows for a rigorous analysis of partial deposit insurance and provides the first comparative statics of the optimal level of deposit coverage. The optimal amount of coverage increases with lower bank liquidity requirements, with a higher precision of depositors' information, and with a lower relevance of large, uninsured creditors, and it should not be increased in anticipation of an economic downturn. Optimal insurance is higher if there is contagion and lower if banks can assume excessive risk, but interestingly, a high level of coverage may not be optimal even in the absence of moral hazard on the part of banks. The model supports the inauguration of coinsurance provisions and is applied to compare various policies addressing financial fragility. While an optimal lending of last resort policy can outperform deposit insurance, anticipated bailouts are inferior in terms of welfare. Capital requirements are not a substitute for insurance, but mitigate excessive risk taking.
\end{abstract}

\section{JEL Classifications: G21, G28, C72}

Keywords: deposit insurance, level of coverage, bank runs, global games, systemic risk, moral hazard, coinsurance

Michael Manz is a senior economist at the Swiss National Bank and a visiting scholar at the Federal Reserve Bank of Boston. His email address is michael.manz@snb.ch.

I thank Ernst Baltensperger, Winand Emons, Simon Loertscher, Yvan Lengwiler, Aleksander Berentsen, Mark Flannery, Christina Wang, and two anonymous referees for their comments on an earlier version or for helpful discussions. Any remaining errors are my own.

This paper, which may be revised, is available on the web site of the Federal Reserve Bank of Boston at http://www.bos.frb.org/economic/wp/index.htm.

The views expressed in this paper are those of the authors and do not necessarily represent those of the Federal Reserve Bank of Boston or the Federal Reserve System.

This version: May 2009 


\section{Introduction}

In order to contain the proliferation of bank runs, many countries have adopted explicit deposit insurance during recent decades. ${ }^{1}$ The major theoretical case for deposit protection relies on models in the style of Diamond and Dybvig (1983), where deposit insurance enables depositors to reap the full benefits of banking at no cost, by eliminating runs as the only source of failure. However, there is now widespread agreement that most bank failures are driven by weaknesses in economic balance sheets rather than by self-fulfilling panics. Thus the adoption of deposit insurance may imply heavy $\operatorname{losses}^{2}$ and involves a tradeoff: Preventing runs is a welcome result if a bank is solvent, but it is less reasonable if depositors have good reason to run and to enforce closure of an insolvent institution. In a nutshell, deposit protection inhibits both inefficient and efficient bank runs and may encourage banks to engage in imprudent practices.

The focus of this paper is on the amount of coverage offered to depositors, which is a key feature governing the tradeoffs surrounding deposit insurance and the centerpiece of any discussion of reforms. While partial insurance may fail to prevent runs, as the experience of U.K. bank Northern Rock in September 2007 well demonstrated, it may strengthen market discipline. This gives rise to the vital question of whether there is an optimal degree of protection. In most countries, we observe partial rather than full deposit insurance, though governments tend to extend protection in the wake of financial turmoil. ${ }^{3}$ Whether the latter is an appropriate measure remains open to debate.

While the basic arguments against or in favor of full deposit insurance seem to be reasonably understood, existing theories offer little, if any, guidance on the optimality of partial insurance. A major difficulty resides in the fact that most bank run models,

\footnotetext{
${ }^{1}$ According to Demirguc-Kunt et al. (2005), the number of countries maintaining explicit deposit insurance has risen to 88 by 2003, which is a quadruple of the 1984 figure.

${ }^{2}$ Benston and Kaufman (1997) report that in the United States, the debacle of insured savings and loan associations in the 1980s alone required some $\$ 150$ billion of taxpayer funds.

${ }^{3}$ For example, in 2008, the coverage limit in the United States was temporarily raised from $\$ 100,000$ to $\$ 250,000$ per depositor as a reaction to the subprime crisis, and European finance ministers agreed to raise the minimal level of deposit insurance from 20,000 to 50,000 euros across the EU.
} 
following Diamond and Dybvig (1983), exhibit multiple equilibria. This makes it hard to assess the difference even between a coverage of 1 percent and 99 percent of deposits. In either case, anything may happen, depending on which equilibrium is selected, which in turn is not explained by the model. To get rid of this indeterminacy, I therefore build on the global games refinement technique, initiated by Carlsson and van Damme (1993). In a global game, players privately observe noisy signals of the underlying state of the world. With strategic complementarities and a minimal precision of signals, this setting establishes a unique equilibrium in many models of coordination failure.

This paper considers a global game model of a bank that is financed by a continuum of small depositors subject to (partial) deposit insurance, by a large uninsured lender, and by the bank owner. The bank is run by a self-interested manager who can influence the riskiness of bank assets. In equilibrium, the behavior and the utilities of all involved agents are a function of the protection level. The model sheds light on how raising the level of insurance mitigates market failures such as a lack of coordination among depositors and how it reinforces other inefficiencies such as excessive risk taking by the banker. In particular, it allows to derive an optimal level of insurance and yields hitherto unnoticed results on comparative statics. Another insight, which is new to the literature, is that a high level of insurance can even be detrimental if the behavior of banks is treated as exogenous. The framework is also useful in exploring the design of deposit insurance and its interaction with lending of last resort, bailouts, and capital regulation.

Various studies investigate the impact of deposit insurance coverage empirically. Demirguc - Kunt and Detragiache (2002), among others, provide evidence that a greater extent of insurance induces more, rather than fewer bank failures. Imai (2006) finds that the switch from a blanket guarantee to limited coverage of time deposits that took place in Japan in 2002 enhanced market discipline. Some other recent studies use experiments to address the impact of partial deposit coverage on bank runs, though the findings are not conclusive. Schotter and Yorulmazer (2009) demonstrate that even partial insurance is effective in diminishing runs, while Madies (2006) does not support this finding.

However, very few theoretical papers deal with the level of deposit coverage. Cooper and Ross (2002) explore a Diamond-Dybvig model with moral hazard. They point out 
that full deposit insurance supports the first best outcome if and only if it is accompanied by optimal capital requirements, and that otherwise partial rather than full insurance can be preferable. Since their model overcomes the problem of indeterminacy by attaching exogenous probabilities to sunspots, the incidence of bank runs is not related to the degree of insurance. By contrast, my model allows for interaction between the level of coverage and the conduct of depositors. Obviously, the paper is also related to the literature on global games. Morris and Shin (2004) provide a model of pricing debt, Corsetti et al. (2004) extend the seminal Morris and Shin (1998) model of speculative attacks to include a large investor, and Goldstein and Pauzner (2005) explore a global game model in a banking context. In another related model, Morris and Shin (2006) show that IMF assistance that reduces coordination failures among investors can increase, or in some cases reduce, debtor country moral hazard.

In light of its pivotal role, deposit coverage deserves more scrutiny. This paper attempts to be a step in filling this gap and offers, to the best of my knowledge, the first unique equilibrium analysis of partial insurance. The model is introduced in Section 2 of the paper. In Section 3, I investigate the role of deposit insurance and the comparative statics of the optimal coverage. Section 4 extends the model to include systemic risk and explores various policy applications of the model. Section 5 concludes.

\section{The Model}

\subsection{Basic Framework}

The model considers a stylized bank that is run by a self-interested bank manager and receives funding from a continuum with mass $(1-\alpha)$ of small dispersed depositors and a single large lender with measure $\alpha$, where $\alpha<1$. There are three periods $t=0,1,2$ and one good. Small and large lenders are born at date 0 with an endowment of 1 and derive utility $u\left(C_{i}\right)$ or $u_{\alpha}\left(C_{\alpha}\right)$ from consumption in period 2 , where $C_{i}\left[C_{\alpha}\right]$ denotes consumption of depositor i [of the large lender], and $u(\cdot)$ and $u_{\alpha}(\cdot)$ are twice continuously differentiable, increasing, and weakly concave functions with $u(0)=u_{\alpha}(0)=0$. There are two productive 
technologies. All agents have access to a storage technology that simply yields one unit at either date 1 or 2 . The bank, in turn, has access to a risky technology that generates either one unit of output if terminated in period 1 or an uncertain but potentially higher payoff if liquidated in period 2. To incorporate a role for equity, assume that the bank owner has an endowment of $\beta$ which is invested in the bank at date 0 . While this evolves as an endogenous choice for some values of the model's parameters, another interpretation is that the bank is subject to binding capital requirements captured by $\beta$.

At $t=0$, the bank issues demandable debt contracts that offer each creditor either a payment of 1 at date 1 or a higher payment at date 2 . Since withdrawing at date 1 involves no risk, it is rational for everyone to become a depositor initially. However, at the intermediate stage 1 , small and large creditors individually and simultaneously decide whether or not to withdraw their funds so as to maximize $E_{1}\left\{u\left(C_{i}\right)\right\}$ or $E_{1}\left\{u_{\alpha}\left(C_{\alpha}\right)\right\}$, respectively, where $E_{1}\{\}$ is the expectations operator conditional on the information set at time $t=1$. In period $t=2$, the bank is liquidated and yields a gross return of

$$
r(\theta, l, v)= \begin{cases}(1+\beta-l)(1+\gamma) & \text { if } \theta>\eta+\xi l+\kappa v \\ 0 & \text { otherwise }\end{cases}
$$

where $\theta$ is a random state drawn from a uniform distribution on the unit interval, $l \in[0,1]$ denotes the mass of (small and large) creditors withdrawing at date 1 , and $v \in[0,1]$ is a risk level chosen by the bank manager. The parameter $\gamma>0$ measures the return of the banking technology if it is successful, whereas $\eta, \xi$, and $\kappa$ are non-negative parameters that characterize the bank's likelihood of default. For simplicity, I assume that the proceeds are evenly shared among eligible claim holders, such that in case of a successful outcome, all creditors are promised a gross return of $(1+\gamma)$ and the residual equity is $\beta(1+\gamma){ }^{4}$

Several aspects of the banking technology deserve some further explanation. First, the stochastic fundamental $\theta$ represents all aspects of the bank's soundness that the banker cannot influence. These can be macroeconomic shocks or bank-specific factors like simply good or bad luck. The parameter $\eta$ defines how likely the fundamentals are to lead to

\footnotetext{
${ }^{4}$ Notice that given the binary nature of the return, seniority of debt is not an issue and claims are indeed equivalent in terms of risk.
} 
bank default irrespective of how the creditors and the banker behave. For example, if the economy is expected to slide into a recession, this can be seen as an increase in $\eta$.

A second crucial feature of the bank's technology is that the more funds are withdrawn at date 1 , the lower is the expected return on the remaining long-term investment. This specification contains the notion of illiquidity due to a market imperfection. In the presence of asymmetric information on the quality of loan portfolios, the bank may suffer from firesale losses when trying to sell its assets before they mature. The negative impact of early withdrawals on long-term investment proceeds is measured by the parameter $\xi$. Roughly speaking, a large value of $\xi$ means that a bank has chosen a low level of liquid reserves or that its assets are particularly illiquid. ${ }^{5}$

Third, the model assumes that the bank manager faces incentives that are not fully compatible with maximizing the wealth of lenders (or even bank owners). Rather, in period 0 , the manager chooses a risk level $v$ to solve the optimization problem

$$
\max _{v \in[0,1]} E_{0}\{\pi(v)\} \equiv P(\theta>\eta+\xi l+\kappa v)[\beta(1+\gamma)+v]
$$

The profit $\pi(v)$ contains the residual claim of bank owners and an additional amount $v$ in case of success, but nothing otherwise. One interpretation of $v$ is that the manager tries to extract a private benefit that increases with risk but is only available if the bank succeeds. Note that a bonus in the form of stock options exhibits exactly this kind of properties. The impact of raising $v$ is twofold: It increases the manager's payoff in case of success but lowers the likelihood of success. The parameter $\kappa$ measures the impact of risk taking on the probability of default. While the creditors in general also benefit from the risky technology, from their perspective any $v>0$ represents excessive risk that they would prefer to avoid. However, suppose that, even though the level of $v$ can be observed, contracts are incomplete and cannot be conditioned on $v .^{6}$

It is worth observing that the usefulness of the bank considered here lies simply in its

\footnotetext{
${ }^{5}$ Since illiquid assets tend to be rewarded with higher returns, $\theta>(\eta-\xi)+\xi l+\kappa v$ might be a more convincing, albeit more complicated, condition for a high return in equation (1). As will be seen in Section 3.3, replacing $\eta$ by $\eta-\xi$ would not alter the comparative static results regarding $\xi$ and $\eta$.

${ }^{6}$ For example, $v$ may be observable but not verifiable or not enforceable. In fact, deposit contracts contingent on management behavior are not observed in practice.
} 
ability to run an investment technology to which individuals have no access. Since all agents consume in period 2, there is no need for bank contracts to offer liquidity insurance. Rather than deriving an optimal contract endogenously, the model takes as given that the bank issues demand deposits, as is observed in the real world. One reasonable story to justify such contracts could be the argument of Calomiris and Kahn (1991) that demandable debt serves as a disciplinary tool to prevent bankers from absconding with the funds of depositors. As is shown below, there is a similar mechanism at work in this model.

The model is put in a global game framework by assuming that the distribution of the fundamental variable is common knowledge but the state $\theta$ is not. Instead, creditors privately observe noisy signals of the true $\theta$ at time 1 , before deciding whether to withdraw. It seems natural to expect the large lender, representing a sophisticated or institutional investor, to be better informed than small depositors. For simplicity, suppose that the large lender observes $\theta$ without noise, while each small depositor $i$ observes a signal

$$
s_{i}=\theta+\varepsilon_{i},
$$

where the random term $\varepsilon_{i}$ is uniformly distributed on $[-\varepsilon, \varepsilon]$ and independent of $\theta$ and of $\varepsilon_{j} \forall j \neq i .^{7}$ In addition, the following restrictions on the parameters are imposed:

$$
\begin{gathered}
0<\eta<1-\xi-\kappa, \\
2 \varepsilon \leq \min [\eta, 1-\eta-\xi-\kappa] .
\end{gathered}
$$

Assumption (5) ensures that the signal is of some minimal quality. The restrictions in (4) in turn imply that there is at least one state $\theta<\eta$ in which the bank fails even if no creditor withdraws at $t=1$ and risk level $v=0$, and at least one state $\theta>\eta+\xi+\kappa$ in which the bank succeeds even if everyone withdraws in the intermediate period and if the risk level is $v=1$. So for some extreme states of nature, creditors have dominant actions.

Deposit insurance is now incorporated in the following way: If the bank fails, the government or a private insurer steps in and immediately pays out an amount $\chi \in[0,1+\gamma]$ at date $t=2$ to all insured depositors who have not yet withdrawn their funds. In order to

\footnotetext{
${ }^{7}$ For a discussion of varying the relative signal precision of the large investor, see Corsetti et al. (2004), who were the first to consider small and large investors in a global game model of speculative attacks.
} 
capture the fact that real banks have both insured and uninsured liabilities on their balance sheets, I assume that deposits of the small creditors are insured, while the claims of the large lender are not. The large (institutional) lender can be interpreted as providing shortterm financing on a rollover basis other than core deposits. To cover potential outlays, the insurer collects premiums (or taxes) from insured depositors, such that their payoff is reduced by an amount $\tau$ independently of their withdrawing behavior. ${ }^{8}$ Both policy parameters $\chi$ and $\tau$ are publicly and credibly announced at $t=0$. The objective of the insurer is to choose a coverage level $\chi$ to maximize the ex ante welfare function

$$
W(\chi)=(1-\alpha) E_{0}\left\{u\left(C_{i}\right) \mid \chi\right\}+w_{\alpha} \alpha E_{0}\left\{u_{\alpha}\left(C_{\alpha}\right) \mid \chi\right\}+w_{\pi} E_{0}\{\pi \mid \chi\}-c(1-\alpha) \tau,
$$

where $w_{\alpha}$ and $w_{\pi}$ are the relative weights given to the payoffs of the large lender and the banker, respectively, subject to a probabilistic budget constraint

$$
(1-\alpha) \tau=\chi P(\theta \leq \eta+\xi l+\kappa v) E_{0}\{1-\alpha-\widetilde{l} \mid \theta \leq \eta+\xi l+\kappa v\},
$$

where $\tilde{l}$ denotes the mass of insured depositors withdrawing at $t=1$. Potential costs of raising the required funds are captured in the above welfare function by subtracting an amount proportional to aggregate taxes $(1-\alpha) \tau$, and the parameter $c \geq 0$ represents constant marginal costs of collecting taxes such as distortions or administrative costs. The constraint (7) manifests that the premiums levied upon depositors must cover expected, rather than actual, equilibrium expenses. This would approximately hold if deposit insurance were financed by many independent banks or in a repeated game where the insurer must run a balanced budget on average, but not in every period.

The payoffs of agents are summarized in Table 1, and the timing of events is as follows:

- $t=0$ : The insurer announces $\chi$ and $\tau$. Creditors and the bank owner invest in the bank. The banker chooses $v$. Nature determines $\theta$.

- $t=1$ : The creditors observe signals on $\theta$ and decide whether to withdraw.

- $t=2$ : The bank is liquidated. The proceeds, if any, are shared as contracted. If the bank fails, insured depositors that have not withdrawn at $t=1$ are reimbursed an amount $\chi$. All insured depositors pay a tax $\tau$. Then agents consume.

\footnotetext{
${ }^{8}$ Assuming that premiums are paid by the bank but that insured depositors are offered a lower contracted return than uninsured creditors and owners would imply a similar distribution of the burden.
} 
Table 1: Summary of payoffs

\begin{tabular}{|l||l|l||l|l||c||}
\hline \multicolumn{1}{|c||}{} & \multicolumn{2}{c||}{ small depositors } & \multicolumn{2}{c||}{ large lender } & banker \\
\cline { 2 - 6 } & withdraw & roll over & withdraw & roll over & select $v$ \\
\hline \hline$\theta>\eta+\xi l+\kappa v$ & $u(1-\tau)$ & $u(1+\gamma-\tau)$ & $u_{\alpha}(1)$ & $u_{\alpha}(1+\gamma)$ & $\beta(1+\gamma)+v$ \\
\hline$\theta \leq \eta+\xi l+\kappa v$ & $u(1-\tau)$ & $u(\chi-\tau)$ & $u_{\alpha}(1)$ & 0 & 0 \\
\hline
\end{tabular}

\subsection{Unique Equilibrium}

A small depositor's [the large creditor's] strategy is a plan that states whether or not to withdraw at $t=1$ for each signal $s_{i} \in[-\varepsilon, 1+\varepsilon$ ] [for each possible observation $\theta$ ] and for each risk level $v$. The banker's strategy is to select a risk level $v$ subject to $v \in[0,1]$ for all possible actions of creditors. In an equilibrium profile of strategies, each agent's strategy maximizes her expected utility, given her beliefs about the types of the other players, and provided that all other players follow the strategies in the profile. Moreover, the insurer's choice of $\chi$ and $\tau$ must satisfy the probabilistic budget constraint. The main result of this subsection is the following proposition, which is proved in the appendix:

Proposition 1 For any $\chi \in[0,1+\gamma]$, there is a unique Bayesian Nash equilibrium in which small creditors leave their deposits in the bank if and only if their signal exceeds a threshold $s^{*}(\chi)$, the large lender rolls over and the bank succeeds if and only if $\theta$ exceeds a threshold $\theta^{*}(\chi)$, the banker chooses a risk level $v^{*}(\chi)$, and a sufficient condition for the premium $\tau^{*}(\chi)$ being uniquely determined $\forall \chi \in[0,1+\gamma]$ is $\frac{-\chi u^{\prime \prime}(C)}{u^{\prime}(C)} \leq \frac{1}{2 \varepsilon} \forall C \in[\chi, 1] .{ }^{9}$

The equilibrium outcome is uniquely determined by the realization of the fundamental $\theta$, which allows us to assess the likelihood of bank failure, the incidence of specific types of behaviors, and the ex ante expected utilities of all agents. Small depositors withdraw at date 1 with probability $P\left[s_{i} \leq s^{*}(\chi)\right]$, in which case they achieve utility $u\left(1-\tau^{*}(\chi)\right)$. If a depositor spots a signal higher than $s^{*}(\chi)$, two cases have to be distinguished: If $\theta>\theta^{*}(\chi)$,

\footnotetext{
${ }^{9}$ For example, a CRRA utility with a coefficient of relative risk aversion not exceeding $\frac{1}{2 \varepsilon}$, which is a number between 2 and infinity, would meet this requirement. Without such a restriction, it cannot be excluded that there may be utility functions for which more than one choice of $\tau$ satisfies the budget constraint. This would not affect the uniqueness of equilibrium once a particular $\tau$ is chosen, but might imply that different levels of $\tau$ are consistent with a given $\chi$.
} 
the resulting utility is $u\left(1+\gamma-\tau^{*}(\chi)\right)$, whereas if $\theta \leq \theta^{*}(\chi)$, a depositor ends up with utility $u\left(\chi-\tau^{*}(\chi)\right)$. The large lender receives $u_{\alpha}(1+\gamma)$ with probability $P\left[\theta>\theta^{*}(\chi)\right]$ or $u_{\alpha}(1)$ with probability $P\left[\theta \leq \theta^{*}(\chi)\right]$, and the banker obtains $\beta(1+\gamma)+v^{*}(\chi)$ if $\theta>\theta^{*}(\chi)$ but 0 otherwise. Thus the equilibrium payoffs can be derived as

$$
\begin{aligned}
E_{0}\left\{u\left(C_{i}\right) \mid \chi\right\}= & P\left[s_{i} \leq s^{*}(\chi)\right] u\left(1-\tau^{*}(\chi)\right) \\
& +P\left[\left(s_{i}>s^{*}(\chi)\right) \cap\left(\theta>\theta^{*}(\chi)\right)\right] u\left(1+\gamma-\tau^{*}(\chi)\right) \\
& +P\left[\left(s_{i}>s^{*}(\chi)\right) \cap\left(\theta \leq \theta^{*}(\chi)\right)\right] u\left(\chi-\tau^{*}(\chi)\right), \\
E_{0}\left\{u_{\alpha}\left(C_{\alpha}\right) \mid \chi\right\}= & P\left[\theta \leq \theta^{*}(\chi)\right] u_{\alpha}(1)+P\left[\theta>\theta^{*}(\chi)\right] u_{\alpha}(1+\gamma), \\
E_{0}\{\pi \mid \chi\}= & P\left[\theta>\theta^{*}(\chi)\right]\left(\beta(1+\gamma)+v^{*}(\chi)\right),
\end{aligned}
$$

where the according probabilities are given by

$$
\begin{aligned}
P\left[\theta \leq \theta^{*}(\chi)\right] & =\theta^{*}(\chi), \\
P\left[s_{i} \leq s^{*}(\chi)\right] & =\left\{\begin{array}{ll}
s^{*}(\chi) & \text { if } \chi \leq 1 \\
0 & \text { if } \chi>1
\end{array},\right. \\
P\left[\left(s_{i}>s^{*}(\chi)\right) \cap\left(\theta>\theta^{*}(\chi)\right)\right] & =\left\{\begin{array}{ll}
1-s^{*}(\chi)-\frac{\left(\theta^{*}(\chi)-s^{*}(\chi)+\varepsilon\right)^{2}}{4 \varepsilon} & \text { if } \chi \leq 1 \\
1-\theta^{*}(\chi) & \text { if } \chi>1
\end{array},\right. \\
P\left[\left(s_{i}>s^{*}(\chi)\right) \cap\left(\theta \leq \theta^{*}(\chi)\right)\right] & =\left\{\begin{array}{ll}
\frac{\left(\theta^{*}(\chi)-s^{*}(\chi)+\varepsilon\right)^{2}}{4 \varepsilon} & \text { if } \chi \leq 1 \\
\theta^{*}(\chi) & \text { if } \chi>1
\end{array} .\right.
\end{aligned}
$$

The equilibrium payoffs can now be used to assess welfare $W(\chi)$ and to derive an optimal level of $\chi$. Yet before doing so, it seems worthwhile to reflect on the sources of market failure and on the role of deposit insurance in more detail.

\section{Analysis of the Optimal Coverage}

\subsection{Sources of Market Failure}

It is essential to recognize that the equilibrium is inefficient and leaves room for improvement, which could serve as a justification for adopting deposit insurance in the first place. There are three sources of inefficiencies. First, bank runs can be inefficient. To provide more accuracy on the subject, Table 2 divides the state of fundamental $\theta$ into four cases: 
Table 2: Status of bank and role of bank runs

\begin{tabular}{|l|l|l|l|}
\hline fundamental state $\theta$ & status of bank & $\begin{array}{l}\text { marginal cause } \\
\text { of failure }\end{array}$ & $\begin{array}{l}\text { role of bank } \\
\text { runs }\end{array}$ \\
\hline \hline$\theta \leq \eta$ & insolvent and illiquid & nature & efficient \\
\hline$\eta<\theta \leq \eta+\kappa v^{*}(\chi)$ & insolvent and illiquid & banker & efficient \\
\hline$\eta+\kappa v^{*}(\chi)<\theta \leq \theta^{*}(\chi)$ & solvent but illiquid & depositors & inefficient \\
\hline$\theta>\theta^{*}(\chi)$ & solvent and liquid & none & not effective \\
\hline
\end{tabular}

If $\theta$ falls short of the solvency threshold $\eta+\kappa v^{*}(\chi)$, the bank is fundamentally insolvent and fails even if no creditor withdraws. If $\theta$ is even lower than $\eta$, the bank fails irrespective of the banker's choice of risk, whereas if $\eta<\theta \leq \eta+\kappa v^{*}(\chi)$, the (marginal) blame for failure is on the bank manager. In either case, the bank should be liquidated before date 2 , and runs are efficient. However, it can also be shown that $\theta^{*}(\chi)>\eta+\kappa v^{*}(\chi)$. This implies that for all states $\theta \in\left(\eta+\kappa v^{*}(\chi)\right), \theta^{*}(\chi)$, the bank fails only because depositors are unable to coordinate their actions, thereby triggering the collapse of a solvent but illiquid institution. These bank runs are inefficient. Thus, the coordination failure entails a failure threshold that is higher than optimal from a welfare point of view.

The second source of market failure is excessive risk taking by the bank manager. This inefficiency arises due to an externality because the manager, ignoring the impact on creditors, tends to assume excessively high risk. This occurs whenever $v^{*}(\chi)$ exceeds 0 .

A third and more subtle inefficiency resides in the fact that because of their noisy information, depositors are prone to make suboptimal choices in equilibrium. Drawing on the language of statistics and presuming a null hypothesis of a successful bank, they may commit either type I or type II errors, which are illustrated in Table 3. On the one hand, if $\chi<1$, they may forgo an amount $\gamma$ by withdrawing although the bank survives. The probability $e_{I}(\chi)$ of this type I or "overpessimistic" error is

$$
e_{I}(\chi)=P\left[\left(s_{i} \leq s^{*}(\chi)\right) \cap\left(\theta>\theta^{*}(\chi)\right)\right]=\left\{\begin{array}{ll}
\left(s^{*}(\chi)-\theta^{*}(\chi)+\varepsilon\right)^{2} / 4 \varepsilon & \text { if } \chi \leq 1 \\
0 & \text { if } \chi>1,
\end{array} .\right.
$$

On the other hand, depositors may leave their funds in a collapsing bank, in which case it would have been more efficient to withdraw. The likelihood of this type II or "overconfident" error, henceforth denoted $e_{I I}(\chi)$, is given by equation (14). If $\chi$ exceeds a level $\tilde{\chi}$, 
depositors may even desist from withdrawing if the bank is insolvent, which is a particularly inefficient kind of type II error. ${ }^{10}$

Table 3: Types of errors

\begin{tabular}{|l|l|l|l|l|l|}
\hline $\begin{array}{l}\text { depositor's } \\
\text { signal }\end{array}$ & state $\theta$ & $\begin{array}{l}\text { type of } \\
\text { error }\end{array}$ & payoff & $\begin{array}{l}\text { payoff } \\
\text { forgone }\end{array}$ & $\begin{array}{l}\text { probability of } \\
\text { the event }\end{array}$ \\
\hline \hline$s_{i} \leq s^{*}(\chi)$ & $\theta \leq \theta^{*}(\chi)$ & none & $1-\tau^{*}(\chi)$ & 0 & $\theta^{*}(\chi)-e_{I I}(\chi)$ \\
\hline$s_{i} \leq s^{*}(\chi)$ & $\theta>\theta^{*}(\chi)$ & type I & $1-\tau^{*}(\chi)$ & $\gamma$ & $e_{I}(\chi)$ \\
\hline$s_{i}>s^{*}(\chi)$ & $\theta \leq \theta^{*}(\chi)$ & type II & $\chi-\tau^{*}(\chi)$ & $\max [1-\chi, 0]$ & $e_{I I}(\chi)$ \\
\hline$s_{i}>s^{*}(\chi)$ & $\theta>\theta^{*}(\chi)$ & none & $1+\gamma-\tau^{*}(\chi)$ & 0 & $1-\theta^{*}(\chi)-e_{I}(\chi)$ \\
\hline
\end{tabular}

\subsection{The Role of Deposit Insurance Coverage}

The vital question arising from the preceding discussion is how these inefficiencies are affected by deposit insurance. In this section, I show that the level of coverage is the driving feature both in mitigating some market failures and in reinforcing some other inefficiencies. The consequences of varying the coverage $\chi$ can be summarized as follows:

Proposition $2 \forall \chi \in[0,1+\gamma]$, the functions $s^{*}(\chi), \theta^{*}(\chi), \tau^{*}(\chi), v^{*}(\chi), e_{I}(\chi)$, and $e_{I I}(\chi)$ are continuous in $\chi$, with the exception that $s^{*}(\chi), \tau^{*}(\chi)$, and $e_{I I}(\chi)$ are discontinuous at $\chi=1$. The slopes with respect to $\chi$ are

(i) $\frac{d s^{*}(\chi)}{d \chi}<\frac{d \theta^{*}(\chi)}{d \chi}<0 \forall \chi<1, \frac{d s^{*}(\chi)}{d \chi}=\frac{d \theta^{*}(\chi)}{d \chi}=0 \forall \chi>1$,

ii) $\quad \frac{d e_{I}(\chi)}{d \chi}<0 \forall \chi<1, \frac{d e_{I}(\chi)}{d \chi}=0 \forall \chi>1$,

(iii) $\frac{d e_{I I}(\chi)}{d \chi}>0 \forall \chi<1, \frac{d e_{I I}(\chi)}{d \chi}=0 \forall \chi>1$,

(iv) $\frac{d \tau^{*}(\chi)}{d \chi}>0 \forall \chi<1$ and $\forall \chi>1$, and

(v) $\quad \frac{d v^{*}(\chi)}{d \chi} \geq 0 \forall \chi$.

The proposition is proved in Appendix A.2. In economic terms, the above findings (i) to (v) imply the following effects of raising the degree of deposit insurance:

- (i) more coordination, less bank failure: The major benefit of augmenting the degree of insurance is to reduce the extent of coordination failure and thereby the

${ }^{10} \tilde{\chi}$ is the unique value of $\chi$ solving $s^{*}(\chi)=\eta+\kappa v^{*}(\chi)+\varepsilon$, where $s^{*}(1)=\eta+\kappa v^{*}(\chi)-\varepsilon, \frac{d s^{*}}{d \chi}<0$ and $\frac{d v^{*}}{d \chi} \geq 0$ (see Proposition 2) imply $\tilde{\chi}<1$. 
threshold $\theta^{*}(\chi)$. Intuitively, this holds because raising $\chi$ induces depositors to leave their funds in the bank for a larger range of signals.

- (ii) less overpessimistic errors: A second advantage is that a higher $\chi$ renders it less likely that bank customers withdraw their deposits from a sound institution, because the increase in depositors' confidence is more than proportional to the decrease in the likelihood of bank failure.

- (iii) more overconfident errors: However, the same logic also implies that a higher coverage $\chi$ raises the proportion of depositors leaving their funds in a failing, perhaps even insolvent bank. This moral hazard type behavior of depositors always implies a waste of resources, even if $\chi \geq 1$, because the insurer must pay for the lost funds, a cost that is reflected in the equilibrium premium.

- (iv) higher taxes and distortions: As a consequence, increasing $\chi$ involves higher taxes. Even though extending $\chi$ lowers the likelihood of bank failure, it fails to do so substantially enough so as to compensate for the higher costs in case of failure. This also entails higher tax distortions, as supposed in the welfare function.

- (v) higher excessive risk: A final pitfall of high coverage is to increase excessive risk taking by bank managers. The intuition behind this result is straightforward: While deposit insurance does not affect the manager's benefit which — in case of success - increases with risk, a higher $\chi$ mitigates the negative impact of risk taking on the likelihood of success, and hence induces the banker to assume higher risk.

A further and trivial source of improvement is that deposit insurance balances payoffs across states of nature, which is always beneficial if agents are risk averse. However, this is neither the specific nor the really interesting impact of deposit insurance, which is typically recognized to be a tool preventing bank panics but inevitably evoking unintended incentives. If protecting households from adverse wealth shocks were the major purpose, it would seem more compelling to envision the adoption of wealth insurance that covers also bond and stock holdings, real estate, and other assets. Thus, the case of risk neutrality, to which I turn next, has the advantage not only of being analytically tractable, but also of 
allowing us to focus on the incentives that are specific to deposit insurance rather than on generic aspects of insurance provision. ${ }^{11}$

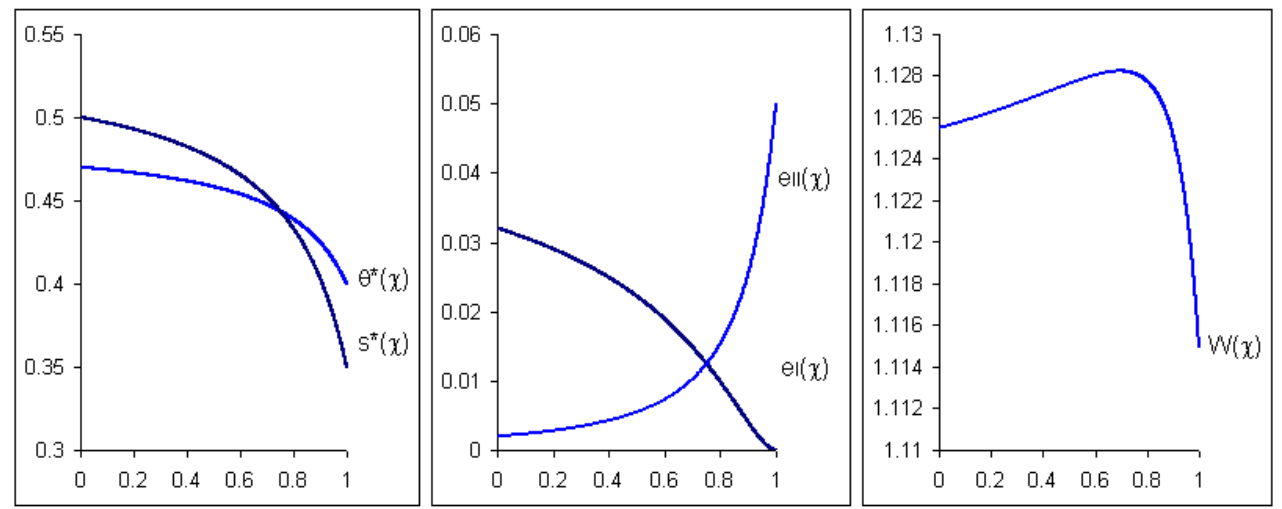

Figure 1: Thresholds and welfare

with $u(C)=u_{\alpha}(C)=C, \eta=0.1, \kappa=\alpha=0.3, \varepsilon=0.05$,

$\xi=\gamma=0.25, \beta=0.8, w_{\alpha}=1$ and $w_{\pi}=c=0$.

The results of Proposition 2 corroborate the idea that deposit insurance may play a beneficial role, yet the costs of augmenting the level of coverage can eventually outweigh the benefits. Figure 1 provides an example of how the thresholds and probabilities $\theta^{*}(\chi)$, $s^{*}(\chi), e_{I}(\chi), e_{I I}(\chi)$, and welfare depend on $\chi$.

\subsection{Optimal Coverage and Comparative Statics}

While, in general, solving for the optimal $\chi$ has to be done numerically, the model with risk neutrality is analytically solvable and implies the following result:

Proposition 3 (i) If $u(C)=u_{\alpha}(C)=C$ and $w_{\pi}=0,{ }^{12}$ there are thresholds $\underline{\xi}, \bar{\xi}, \underline{\beta}$, and

\footnotetext{
${ }^{11}$ In this context, it is interesting to observe that the bank contracts in the literature on bank runs provide insurance against liquidity risk (see, for example, Goldstein and Pauzner, 2005), but not against the "technology risk" of a poor state of nature. Considered over a whole lifespan, the former is the risk of having to consume more in some years than in others, while the latter is the risk of irrevocably losing all of one's savings, which is certainly no less significant. This is not denying that liquidity insurance may matter, but the most significant effect of introducing deposit insurance in such a model would be risk sharing across states of technology, which is neglected by the contracts considered.

${ }^{12}$ Assuming that the insurer ignores the profit of the banker simplifies computations and precludes the perverse influence of an insurer trying to maximize the benefit $v$ from excessive risk taking.
} 
$\bar{\beta}$, where $\bar{\xi}>\underline{\xi}$ and $\bar{\beta}>\underline{\beta}$, such that the optimal level of coverage is

$$
\chi^{*}= \begin{cases}0 & \text { if } \xi<\underline{\xi}, \text { or if } \underline{\xi} \leq \xi<2 \underline{\xi} \text { and } \underline{\beta} \leq \beta \leq \bar{\beta} \\ \chi_{I}^{*} & \text { if } \underline{\underline{\xi}} \leq \xi \leq 2 \bar{\xi} \text { and } \underline{\beta} \leq \beta \leq \bar{\beta} \\ \chi_{I I}^{*} & \text { if } \underline{\xi} \leq \xi \leq \bar{\xi} \text { and } \beta<\underline{\beta}, \text { or if } \underline{\xi} \leq \xi \leq \bar{\xi} \text { and } \beta>\bar{\beta} \\ 1 & \text { otherwise, }\end{cases}
$$

where $\chi_{I}^{*}=\frac{(1+\gamma)\left[\xi\left(1+\alpha\left(w_{\alpha}-1\right)\right)-2 \varepsilon c\right]}{\left(1+\alpha\left(w_{\alpha}-1\right)\right)+2 \varepsilon(2+c)}$ and $\chi_{I I}^{*}=\frac{(1+\gamma)\left[\xi\left(1+\alpha\left(w_{\alpha}-1\right)\right)-\varepsilon c\right]}{\left(1+\alpha\left(w_{\alpha}-1\right)\right)+\varepsilon(2+c)}$.

(ii) The optimal coverage with an exogenous $v$ is $\chi_{v}^{*}=\min \left[\max \left[\chi_{I I}^{*}, 0\right], 1\right]$, where $\chi_{v}^{*} \geq \chi^{*}$.

A first notable insight from Proposition 3 (ii) is that partial or zero, rather than full, deposit insurance can be optimal even if excessive risk taking is not taken into account. ${ }^{13}$ The reason for this conclusion is again that high coverage undermines the incentives of depositors to engage in bank runs even if these are efficient. However, the most interesting corollary is that the model provides clear-cut comparative statics of an increase in the level of insurance, which are summarized in Table $4 .{ }^{14}$

Table 4: Comparative statics of optimal coverage

\begin{tabular}{|l|l|l|l|l|l|l|l|l|l|l|}
\hline Parameter & $\xi$ & $\eta$ & $\varepsilon$ & $\alpha$ & $\gamma$ & $c$ & $\kappa$ & $\beta$ & $w_{\alpha}$ & $w_{\pi}$ \\
\hline Impact on $\chi^{*}$ & + & 0 & - & - & + & - & 0 & 0 & + & $+^{*}$ \\
\hline
\end{tabular}

${ }^{*}$ If the assumption $w_{\pi}=0$ is relaxed.

Some of these results appear more obvious than others. First, it comes as a small surprise that the optimal coverage increases with a growing impact $\xi$ of illiquidity. Therefore, a high level of deposit insurance is less needed in an environment of highly developed and liquid financial markets. What may be less obvious is that imposing stricter liquidity requirements, which can be interpreted as lowering $\xi$, should come along with choosing a lower $\chi$. In other words, tightening liquidity regulation while at the same time extending protection is not supported by the model.

\footnotetext{
${ }^{13} \mathrm{~A}$ proof of the proposition is sketched in the appendix. Strictly speaking, full coverage amounts to $\chi=1+\gamma$ and is never optimal if $c>0$, but in the following I also refer to $\chi=1$ as full insurance.

${ }^{14}$ The sign of the effects is only weakly positive or negative, for in the extreme cases where full or no insurance is optimal, there is, of course, no further impact of a change in any parameter.
} 
A second notable conclusion is that $\chi^{*}$ does not depend on $\eta$, which seems to be less intuitive. Since $\eta$ characterizes macroeconomic factors influencing expected bank profitability, one might expect it to play a vital role. By contrast, the model implies that if a government believes that a partial coverage is best during a boom, it should not switch to unlimited protection if expecting a recession. Although a growing $\eta$ has an adverse impact on welfare, there is nothing deposit insurance can do about it. Government guarantees are not a panacea for safeguarding banks from an economic downturn.

Third, $\chi^{*}$ depends negatively on the dispersion $\varepsilon$ of the signal, which is also a surprising or even paradoxical result at first glance. The better depositors are informed, the more they should be insured. This result emerges from the fact that the main benefit of raising $\chi$, manifesting itself in a lower threshold $\theta^{*}(\chi)$, does not depend on $\varepsilon$, whereas the costs of a higher $\chi$ captured by $e_{I I}(\chi)$ are increasing in $\varepsilon$. With regard to policy issues, this means that increasing transparency, which amounts to lowering $\varepsilon$, calls for a higher rather than a lower extent of deposit insurance.

As a fourth interesting implication, the larger the uninsured lender is, the lower is the optimal degree of coverage. The intuition behind this result is that the existence of a large lender helps to reduce the amount of coordination failure and thereby makes deposit insurance less needed, which involves a lower optimal coverage.

Fifth, $\chi^{*}$ depends positively on $\gamma$. This is not surprising insofar as a higher return on bank assets renders it more attractive to lower the likelihood of failure, which, in turn, is achieved by augmenting $\chi$. Yet one should bear in mind that $\gamma$ is the return only in case of a good state of nature, whereas the ex ante expected return is also a function of risk and depends in a more complex manner on $\chi$. A sixth result is that higher administrative costs or tax distortions $c$ call for lower coverage, as would be expected.

Turning to the parameters that characterize risk taking by the banker, the impact $\kappa$ of the chosen risk level on bank failure and the equity $\beta$ do not affect the optimal $\chi$; the latter, in particular, may be surprising. Although the chosen risk $v^{*}$ is a function of $\beta$, the way $v^{*}$ depends on $\beta$ is not affected by $\chi$, that is, $\frac{d^{2} v}{d \chi d \beta}=0$. More importantly, however, part (ii) of Proposition 3 indicates that the optimal coverage is (weakly) higher if the risk level $v$ is exogenous, confirming that moral hazard or even the potential for looting on the 
part of banks calls for a lower $\chi$.

Table 4 further shows that $\chi^{*}$ is increasing in the weights $w_{\alpha}$ and $w_{\pi}$ attached to the utilities of the uninsured lender and the banker, implying that the more the insurer cares about insured depositors, the less insurance she should grant them. Though this conclusion again sounds puzzling, the reason behind it is intuitive. While all claim holders benefit from the lower likelihood of failure associated with high coverage, the costs are ultimately borne by the insured depositors. The model thus suggests that banks, and in particular institutions that depend heavily on core deposits (that is, exhibit a low $\alpha$ ) such as small banks, should be most interested in lobbying for an extension of coverage. This is exactly what was observed during the history of deposit insurance in the United States. ${ }^{15}$

\section{Extensions and Policy Applications}

\subsection{Optimal Coverage with Systemic Risk}

One argument brought forward in favor of inaugurating deposit insurance is that if bank runs are contagious, preventing them is particularly relevant. While a rigorous discussion of systemic risk is beyond the purpose of this paper, it is nonetheless interesting to explore the implications for deposit insurance in a stylized extension of the model. Consider $N$ banks indexed by $i=1,2, \ldots, N$, each of which is financed by a continuum of depositors and exhibits a gross return that depends on an independent draw of the fundamental variable $\theta$. The characteristics of banks are specified as in Section 2.1 with two exceptions that capture contagion: First, suppose that bank $i=1$ is systemically relevant because it has an impact on $K$ other banks indexed by $i=N-K+1, \ldots, N$, while the remaining $N-K-1$ institutions, indexed by $i=2, \ldots, N-K$, are immune to contagion. More specifically, for all susceptible banks $i \in\{N-K+1, \ldots, N\}$ the parameter $\eta_{i}$ is $\eta_{i}=\underline{\eta}$ if bank 1 survives and $\eta_{i}=\bar{\eta}$ if bank 1 fails, where $\underline{\eta}<\eta<\bar{\eta}$ and $1 \leq K<N$. For all other banks $i \in\{1,2, \ldots, N-K\}$, presume $\eta_{i}=\eta$. Second, I assume a sequential setting in which depositors of the $K$ susceptible banks observe whether bank 1 fails before they

\footnotetext{
${ }^{15}$ See, for example, the discussion in White(1997).
} 
decide whether to withdraw early.

An obvious cause for a such a linkage could be that $K$ banks are substantial creditors of bank 1 . Thus the fraction $\frac{K}{N}$ is a measure of systemic risk. For analytical purposes, let $\chi_{i}^{*}$ be the optimal coverage on deposits of bank $i$ if the coverage is allowed to be different across banks and $\chi_{C}^{*}$ be the optimal coverage if the restriction $\chi_{i}=\chi \forall i$ is imposed. The benchmark $\chi^{*}$ stems from a model without contagion, where $\eta_{i}=\eta \forall i$. Furthermore, let $w_{1}$ be the weight that the insurer gives to the utility of creditors of bank 1 , whereas the weight of each remaining group of lenders is normalized to one and bankers receive zero weight (that is, $w_{\pi}=0 \forall i$ ). Under risk neutrality, we can then prove the following results, as is shown in Appendix A.4:

Proposition 4 Whenever $\chi_{C}^{*}$ is an interior solution, that is $\chi_{C}^{*} \in(0,1)$, we have:

(i) $\chi_{C}^{*}>\chi^{*}$.

(ii) $\chi_{C}^{*}$ is increasing with $\frac{K}{N}$.

(iii) $\chi_{1}>\chi_{C}^{*}$ and $\chi_{i}^{*}=\chi^{*} \forall i \neq 1$.

(iv) $\frac{\chi_{1}^{*}}{d w_{1}}<0, \frac{\chi_{i}^{*}}{d w_{1}}=0 \forall i \neq 1$, and $\frac{\chi_{C}^{*}}{d w_{1}}<0$.

The upshot, that systemic risk increases the scope of deposit insurance, is consistent with intuition, though the reason this holds merits closer attention. Conditioning $\eta_{i}$ of $K$ banks on the performance of bank 1 introduces correlation into the model to which depositors of the dependent banks react by running on their bank for more states of $\theta$ if bank 1 fails than if it does not. Yet it is vital to stress that this rational reaction does not call for a higher level of protection. Rather, part (iii) of the proposition shows that if the insurer could discriminate between banks, only bank 1 should be given a higher coverage because of contagion. Results (ii) and (iv) in turn reveal that while depositors of the $K$ susceptible banks benefit from a higher $\chi_{1}^{*}$, bank 1 depositors are actually worse off. Thus, $\chi_{C}^{*}$ is decreasing in $w_{1}$ and increasing in $\frac{K}{N}$. The logic behind offering a higher coverage is simply to reduce the likelihood of failure of a systemically relevant bank, which reduces the emerging negative externality in case of a such failure. 


\subsection{Discussion of Policy Alternatives}

\subsubsection{Optimal Caps versus Optimal Coinsurance}

In the following subsections, the model is applied to address a number of issues regarding the design of deposit insurance and its interaction with related policy interventions. Unless otherwise noted, this discussion assumes that creditors are risk neutral, that the insurer does not care about welfare of the banker (that is, $w_{\pi}=0$ ), that there are no tax distortions (that is, $c=0$ ) and that there is no large lender (that is, $\alpha=0$ ).

One application of the model is to compare a regime with caps, where deposits are protected up to a ceiling $\bar{\chi}$, to a regime with coinsurance, in which the insurer guarantees a proportion $\widehat{\chi}$ of deposits. For this purpose, we need to relax the standard assumption of the literature on bank runs, that depositors withdraw either all funds or nothing at date 1, because this assumption unduly limits the strategy space when it comes to assessing the difference between caps and coinsurance. If depositors are confined to withdrawing either 0 or 1 , they do not care about whether insurance covers 50 percent of deposits or a maximal amount 0.5, for example. Therefore, suppose now that each depositor $i$ withdraws an amount $\omega_{i}\left(s_{i}\right) \in[0,1]$ at $t=1$. The bank's gross return at $t=2$ is still given by equation (1), but now the mass $l$ of funds withdrawn at date 1 is computed as $l=\int_{\forall i} \omega_{i} d i$. In addition, assume that in a cap regime, depositors never withdraw the insured amount $\bar{\chi}$. In either regime, there exists a unique equilibrium and an optimal level of deposit coverage. However, the model reveals a remarkable difference in the performance of the two regimes in terms of welfare:

Proposition 5 If $\bar{\chi}$ and $\hat{\chi}$ are set optimally, welfare is strictly higher in a scheme of coinsurance than in a scheme with a cap, unless the optimal coverage is zero.

The proposition, a proof of which is sketched in Appendix A.5, suggests that an optimal design should involve coinsurance. The intuition behind this conclusion is that depositors tend to leave more funds in failing banks in a system with caps. This entails higher premiums, thereby more than offsetting the benefit of a lower failure threshold. 


\subsubsection{Deposit Insurance, Lending of Last Resort, and Bailouts}

I now turn to investigate deposit insurance in combination with other forms of liquidity or solvency assistance. On the one hand, consider a lender of last resort (LolR) that steps in at date 1 to compensate for any funds withdrawn by the creditors if and only if the bank is solvent, that is, whenever $\theta>\eta+\kappa v$. The efficiency of this policy clearly depends on how precisely the LolR can assess the state $\theta$. In the following, I focus on the benchmark of a "perfect" LolR that observes $\theta$ without noise and combines liquidity assistance with disclosing the true state $\theta$ to the public at date $t=1$. On the other hand, I explore an unconditional full bailout policy where the government pays $1+y$ to all debt holders - or even bank owners - irrespective of whether the bank is solvent. Naturally, creditors still have to pay the required level of taxes. Let $W^{\text {lolr }}(\chi)$ and $W^{b}(\chi)$ be the resulting welfare if deposit insurance is combined with an optimal LolR policy or a bailout guarantee, while $W\left(\chi^{*}\right)$ still denotes welfare under optimal deposit insurance alone. The implications for deposit insurance and welfare can then be summarized as follows:

Proposition 6 (i) $\frac{d W^{l o l r}(\chi)}{d \chi}=\frac{d W^{b}(\chi)}{d \chi}=0 \forall \chi<1$, and $\frac{d W^{l o l r}(\chi)}{d \chi}<\frac{d W^{b}(\chi)}{d \chi}=0 \forall \chi>1$.

(ii) $W^{\text {lolr }}(0)>W\left(\chi^{*}\right)>W^{b}(0)$.

(iii) Any intervention that removes the coordination failure among the creditors (weakly) increases excessive risk taking by the borrower.

The results are proved in Appendix 6 and are best understood by assessing how each policy affects the inefficiencies discussed in Section 3.1. Both the LolR and the bailout policy eliminate the strategic uncertainty among creditors, thereby immunizing the bank from the threat of illiquidity due to early withdrawals. Even though this comes at the cost of increasing risk taking, the positive impact of diminishing the coordination failure dominates. In addition, the inefficiency of overpessimistic withdrawals (type I errors) is also completely suppressed. As a consequence, deposit insurance becomes redundant in combination with either an optimal LolR or with an unconditional bailout policy. The key difference between the policies is that the pure liquidity assistance of the LolR supports efficient withdrawals if the bank is insolvent (that is, prevents type II errors), while bailouts 
do not. Result (ii) thus concludes that the optimal LolR policy outperforms optimal deposit insurance, and the latter dominates an unconditional bailout guarantee.

Some further observations of interest emerge from this analysis. First, recall that since the large lender is precisely informed on $\theta$, offering insurance could affect her behavior only if $\chi \geq 1$. But extending full coverage to protect the large lender is tantamount to bailing out all debtors. This establishes the fact that widening the circle of eligible creditors to include the large lender is never an optimal policy. Second, the same outcome as under a perfect LolR can also be achieved by combining public disclosure of $\theta$ with a contingent deposit insurance, where $\chi=1+\gamma$ if $\theta>\eta+\kappa v$ and $\chi=0$ otherwise, or by adopting a perfect closure policy according to which the bank is shut down at $t=1$ if and only if $\theta \leq \eta+\kappa v .^{16}$

Finally and most remarkably, even seemingly perfect interventions fail to achieve the first best outcome, for Proposition 6 (iii) highlights that a coordination failure among creditors has a disciplinary effect on the borrower. The threat of "unnecessary" withdrawals, which is credible only in the presence of a coordination failure, enables the banker to commit herself to actions in the interest of lenders. Therefore, removing an inefficient coordination failure inevitably enhances another inefficiency residing in the conduct of the borrower. This conclusion is related to the analysis in Morris and Shin (2006), though the context and the mechanisms differ to some extent, and, unlike in their model, the impact here of achieving coordination on moral hazard is unambiguous.

\subsubsection{Capital Adequacy and Moral Hazard}

Another policy instrument that is ubiquitous in banking is capital regulation, which in the model can be interpreted as requiring a minimal level of $\beta$. It has been shown above that the optimal level of deposit insurance does not depend on $\beta$, suggesting that capital requirements are not a direct substitute for deposit protection. However, it obviously follows from the analysis in Appendix A.1 that $\frac{d v^{*}}{d \beta}>0$ at least over some range of $\beta$. Tightening capital adequacy rules can hence serve as a means to (partially) offset the adverse incen-

\footnotetext{
${ }^{16}$ However, the model cannot assess the implications of combining perfect disclosure and unconditional partial deposit insurance, for this would reintroduce multiple equilibria into the model for a range of $\theta$.
} 
tives on risk taking induced by deposit insurance. This bottom line is similar to the finding of Cooper and Ross (2002), though unlike in their case, the first best outcome remains out of reach. The preceding discussion also reveals that imposing capital restrictions is not effective in containing risk taking if bank owners are bailed out.

\section{Conclusions}

The model derived in this paper allows for a rigorous analysis of partial deposit insurance. The benefits of insurance involve eliminating inefficient withdrawals and bank runs due to noisy information and coordination failures, whereas the drawbacks consist of suppressing efficient withdrawals and of inducing excessive risk taking. A hitherto hardly noticed conclusion is that a high level of coverage can even be detrimental if bank risk is exogenous, because it undermines the occurrence of efficient bank runs. An extended version of the model shows that systemic risk calls for a higher level of deposit insurance, albeit only for systemically relevant banks from which contagion emanates, and not for the institutions that are potentially affected by contagion.

A vital contribution of the model is to provide comparative statics of the optimal level of coverage. In particular, the results imply that while tightening liquidity requirements is a substitute for deposit insurance, increasing transparency is not. Rather, the optimal coverage increases with the quality of the information available to depositors. Perhaps surprisingly, the degree of deposit insurance should not vary with expectations regarding the development of the real sector. This suggests that countries that in the past turned to increased or even unlimited deposit insurance as a reaction to a crisis, such as Japan, Turkey, or the United States, would do well to pause for thought on whether this is the right measure to strengthen their banking systems. The model also demonstrates why the presence of large creditors with uninsured claims calls for a lower level of insurance and why a high coverage is foremost in the interest of bankers and uninsured lenders. Moreover, it is consistent with small banks being particularly active lobbyists in favor of extending deposit insurance.

Another key advantage of the model is its applicability to various policy issues. In 
practice, only a small, albeit growing, number of countries maintaining deposit insurance require bank customers to coinsure a proportion of their deposits. ${ }^{17}$ According to the model, however, an optimal design of protection should build on coinsurance rather than on setting caps on insured deposits. It further indicates that deposit insurance becomes redundant in combination with full bailouts or optimal lending of last resort. While an unconditional bailout policy is about as inefficient as it can get, an optimal LolR policy combined with perfect public disclosure comes closest to the first best outcome in terms of welfare. Yet such an optimal policy, which requires protection to be contingent on bank solvency, seems far more demanding and hence less realistic in practice than unconditional deposit insurance. If regulators or central banks cannot precisely assess whether a bank is solvent, interventions are likely to be a mixture of the benchmark policies considered. Investigating these cases opens an interesting avenue for future research.

\section{References}

Benston, G. J and G. Kaufman (1997). "FDICIA after Five Years." Journal of Economic Perspectives, 11(3), 139-158.

Calomiris, C. and C. Kahn (1991). "The Role of Demandable Debt in Structuring Optimal Banking Arrangements." American Economic Review, 81, 497-513.

Carlsson, H. and E. van Damme (1993). "Global Games and Equilibrium Selection." Econometrica, 61(5), 989-1018.

Cooper R. and T. Ross (2002). "Bank Runs: Deposit Insurance and Capital Requirements". International Economic Review, 43(1), 55-72

Corsetti, G., A. Dasgupta, S. Morris and H.S. Shin (2004). "Does One Soros Make a Difference? A Theory of Currency Crises with Large and Small Traders." Review of Economic Studies, 71(1), 87-113

Demirguc-Kunt, A. and E. Detragiache (2002). "Does Deposit Insurance Increase Banking

\footnotetext{
${ }^{17}$ Demirguc-Kunt and Kane (2002, p.179) report that only 17 out of the 71 countries with explicit deposit insurance, including Germany and the United Kingdom, have coinsurance.
} 
System Stability? An Empirical Investigation." Journal of Monetary Economics, 49(7), $1373-1406$.

Demirguc-Kunt, A. and E. J. Kane (2002). "Deposit Insurance Around the Globe: Where Does It Work?" Journal of Economic Perspectives 16(2), 175-196.

Demirg-Kunt, A., B. Karacaovali and L. Laeven (2005). "Deposit Insurance around the World: A Comprehensive Database." World Bank Policy Research Working Paper 3628.

Diamond, D. and P. Dybvig (1983). "Bank Runs, Deposit Insurance and Liquidity." Journal of Political Economy, 91(3), 401-419.

Frankel D., S. Morris and A. Pauzner (2003). "Equilibrium selection in global games with strategic complementarities." Journal of Economic Theory, 108 (1), 1-44.

Goldstein, I. and A. Pauzner (2005). "Demand Deposit Contracts and the Probability of Bank Runs." Journal of Finance, 60(3), 1293-1327.

Imai, M. (2006). "Market discipline and deposit insurance reform in Japan." Journal of Banking and Finance, 30(12), 3433-3452.

Madies, P. (2006). "An Experimental Exploration of Self-Fulfilling Banking Panics: Their Occurrence, Persistence, and Prevention." Journal of Business, 79 (4), 1831-1866.

Morris, S. and H.S. Shin (1998). "Unique Equilibrium in a Model of Self-Fulfilling Currency Attacks." American Economic Review, 88, 587-597.

Morris, S. and H.S. Shin (2004). "Coordination Risk and the Price of Debt." European Economic Review, 48(1), 133-153.

Morris, S. and H.S. Shin (2006). "Catalytic finance: When does it work?" Journal of International Economics, 70, 161-177.

Schotter, A. and T. Yorulmazer (2009). "On the dynamics and severity of bank runs: An experimental study." Journal of Financial Intermediation , 18 (2), 217-241.

White, E. (1997). "The Legacy of Deposit Insurance: The Growth, Spread, and Cost of Insuring Financial Intermediaries." NBER Working Paper 6063. 


\section{A Appendix: Proofs}

\section{A.1 Proposition 1}

The proof begins by treating not only $\chi$, but also $\tau$ and $v$ as given parameters. Focusing on the reduced game among the creditors, we can state the following lemma:

Lemma 1 For any set $\{\chi, \tau, v\}$, where $\chi \in[0,1+\gamma], \tau \in[0, \chi]$ and $v \in[0,1]$, there exist thresholds $s^{*}(\chi, \tau, v)$ and $\theta^{*}(\chi, \tau, v)$ such that the unique equilibrium strategy of each small depositor [of the large lender] is to withdraw at $t=1$ if and only if observing $s_{i} \leq s^{*}(\chi, \tau, v)$ [if and only if observing $\left.\theta \leq \theta^{*}(\chi, \tau, v)\right]$, and the bank fails if and only if $\theta \leq \theta^{*}(\chi, \tau, v)$.

To prove the lemma, assume that small depositors follow switching strategies around a threshold $s$ according to which they withdraw at $t=1$ if and only receiving a signal $s_{i} \leq s$. The mass $\widetilde{l}(s, \theta)$ of small depositors withdrawing at $t=1$ is then

$$
\widetilde{l}(s, \theta)=\int_{\min [\theta-\varepsilon, s]}^{\min [s, \theta+\varepsilon]}(2 \varepsilon)^{-1} d s_{i}= \begin{cases}0 & \text { if } s<\theta-\varepsilon \\ (1-\alpha)[s-(\theta-\varepsilon)] / 2 \varepsilon & \text { if } \theta-\varepsilon \leq s \leq \theta+\varepsilon \\ 1-\alpha & \text { if } s>\theta+\varepsilon\end{cases}
$$

and aggregate withdrawals are $l(s, \theta)=\widetilde{l}(s, \theta)$ if the large lender rolls over and $l(s, \theta)=$ $\widetilde{l}(s, \theta)+\alpha$ otherwise. By solving $\theta=\eta+\kappa v+\xi \widetilde{l}(s, \theta)$ for $\theta$, we obtain a threshold

$$
\underline{\theta}(s)=\frac{2 \varepsilon(\eta+\kappa v)+\xi(1-\alpha)(s+\varepsilon)}{2 \varepsilon+\xi(1-\alpha)} \quad \forall s \in[\underline{s}, \bar{s}]
$$

such that the bank succeeds if and only if $\theta>\underline{\theta}(s)$ provided the large lender rolls over, where $\underline{s} \equiv \eta-\varepsilon$ and $\bar{s} \equiv \eta+\xi(1-\alpha)+\kappa v+\varepsilon$. By complete analogy, there is a unique threshold $\bar{\theta}(s)$ such that the bank succeeds if and only if $\theta>\bar{\theta}(s)$ when the large lender withdraws. Given a trigger point $s$, the marginal impact of the large lender is to select one of the trigger thresholds $\underline{\theta}(s)$ or $\bar{\theta}(s)$, where $\bar{\theta}(s)>\underline{\theta}(s)$. Since the large lender precisely observes $\theta$ and prefers $\underline{\theta}(s)$, which yields the higher payoff $1+\gamma$ for more states of $\theta$, her optimal response to switching strategies around $s$ is to roll over if and only if $\theta>\underline{\theta}(s){ }^{18}$

\footnotetext{
${ }^{18}$ The same logic would apply with noisy signals of the large lender, but her trigger point would refer to her imperfect signal, and the failure threshold of $\theta$ would hence become stochastic.
} 
If depositors switch around $s$ and the large lender around $\underline{\theta}(s)$, the expected utility of a small depositor from rolling over if observing $s_{i}=s$ is

$$
Q(s, \chi, \tau)=P\left(\theta>\underline{\theta}(s) \mid s_{i}=s\right) u(1+\gamma-\tau)+P\left(\theta \leq \underline{\theta}(s) \mid s_{i}=s\right) u(\chi-\tau),
$$

where $P\left(\theta>\underline{\theta}(s) \mid s_{i}=s\right)=\left(\frac{s+\varepsilon-\underline{\theta}(s)}{2 \varepsilon}\right)=\left(\frac{s+\varepsilon-\eta-\kappa v}{2 \varepsilon+\xi(1-\alpha)}\right)$. Equation (18) implies that $Q(\underline{s}, \chi, \tau)=u(\chi-\tau), Q(\bar{s}, \chi, \tau)=u(1+\gamma-\tau)$, and that $\frac{\partial Q}{\partial s}>0 \forall s \in[\underline{s}, \bar{s}]$. Therefore, $\forall \chi \in[0,1]$ there exists a unique value $s^{*}$ of $s$ that solves $Q(s, \chi, \tau)=u(1-\tau)$ for any $\chi \in[0,1]$ and any $\tau \in[0, \chi]$. Denote by $\theta^{*} \equiv \underline{\theta}\left(s^{*}\right)$ the implied switching threshold of the large lender, which is also the failure threshold. If $\chi>1$, no rational small depositor ever withdraws. Equivalently, the switching point $s$ can be defined as $-\varepsilon$ (or any threshold below $-\varepsilon$ ). The trigger threshold of $\theta$ boils down to $\theta^{*}=\eta+\kappa v$ in this case. Clearly, we have shown that switching around $s^{*}$ [around $\theta^{*}$ ] is each small depositor's [the large lender's] best response provided the other creditors follow those strategies, and hence constitutes an equilibrium. Solving equations (18) and (17) yields the following threshold functions:

$$
\begin{aligned}
& s^{*}(\chi, \tau, v)= \begin{cases}\theta^{*}(\chi, \tau, v)+\left(\frac{2 u(1-\tau)-u(1+\gamma-\tau)-u(\chi-\tau)}{u(1+\gamma-\tau)-u(\chi-\tau)}\right) \varepsilon & \text { if } \chi \leq 1 \\
-\varepsilon & \text { if } \chi>1\end{cases} \\
& \theta^{*}(\chi, \tau, v)= \begin{cases}\eta+\kappa v+\left(\frac{u(1-\tau)-u(\chi-\tau)}{u(1+\gamma-\tau)-u(\chi-\tau)}\right) \xi(1-\alpha) & \text { if } \chi \leq 1 \\
\eta+\kappa v & \text { if } \chi>1 .\end{cases}
\end{aligned}
$$

Moreover, it is well known in global games with strategic complementarities that this profile is also the unique equilibrium of the reduced game among creditors, which can be proved as in Morris and Shin (1998) or Frankel et al. (2003). This proves Lemma 1.

In a second step, turning to the problem of the banker, we can prove another lemma:

Lemma 2 For any given parameters $\{\chi, \tau\}$, where $\chi \in[0,1+\gamma]$ and $\tau \in[0, \chi]$, there is a unique optimal choice $v^{*}(\chi, \tau)$ of $v$.

Given Lemma 1 and equation (2), differentiating $E_{0}\{\pi\}$ and solving the first order condition

$$
\frac{d \theta^{*}}{d v}(v+\beta(1+\gamma))=1-\theta^{*}(\chi, \tau, v)
$$

for $v$ yields

$$
\widetilde{v}= \begin{cases}\frac{1-\eta-\beta \kappa(1+\gamma)}{2 \kappa}-\left(\frac{1-\alpha}{2 \kappa}\right)\left(\frac{u(1-\tau)-u(\chi-\tau)}{u(1+\gamma-\tau)-u(\chi-\tau)}\right) \xi & \text { if } \chi \leq 1 \\ \frac{1-\eta-\beta \kappa(1+\gamma)}{2 \kappa} & \text { if } \chi>1\end{cases}
$$


Since $d^{2} E\{\pi\} / d v^{2}<0, \widetilde{v}$ is the optimal $v$ provided it is an interior solution $\widetilde{v} \in[0,1]$. Thus, the unique equilibrium risk level is $v^{*}(\chi, \tau)=\min [\max [\widetilde{v}, 0], 1]$. This proves the lemma.

In a third step, plugging $v^{*}(\chi, \tau)$ into equations (19) and (20) yields functions $s^{*}(\chi, \tau) \equiv$ $s^{*}\left(\chi, \tau, v^{*}(\chi, \tau)\right)$ and $\theta^{*}(\chi, \tau) \equiv \theta^{*}\left(\chi, \tau, v^{*}(\chi, \tau)\right)$, which can be used, together with the budget constraint in (7), to obtain a third intermediate result:

Lemma 3 Let $q(\chi, \tau)$ be the insurer's ex ante expected outlays per depositor. If $\frac{-\chi u^{\prime \prime}(C)}{u^{\prime}(C)} \leq$ $\frac{1}{2 \varepsilon} \forall C \in[\chi, 1]$, there is a unique value $\tau^{*}(\chi)$ of $\tau$ solving $\tau=q(\chi, \tau) \forall \chi \in[0,1+\gamma]$.

Since the insurer pays out all insured depositors who observe a signal $s_{i}>s^{*}(\chi, \tau)$ if the bank fails, i.e. if $\theta \leq \theta^{*}(\chi, \tau), q(\chi, \tau)$ is obtained by multiplying the coverage $\chi$ by the probability of having to reimburse a representative depositor, that is

$$
\begin{aligned}
q(\chi, \tau) & =\chi P\left[\left(s_{i}>s^{*}(\chi, \tau)\right) \cap\left(\theta<\theta^{*}(\chi, \tau)\right)\right] \\
& =\chi \int_{\max \left[s^{*}(\chi, \tau)-\varepsilon, 0\right]}^{\theta^{*}(\chi, \tau)} \int_{s^{*}(\chi, \tau)}^{\theta+\varepsilon} f\left(s_{i} \mid \theta\right) d s_{i} d \theta
\end{aligned}
$$

with $f\left(s_{i} \mid \theta\right)$ being the density of $s_{i}$ conditional on $\theta$. Computing the double integral on the right-hand side of (23) results in

$$
q(\chi, \tau)= \begin{cases}\frac{\chi \Omega^{2}}{4 \varepsilon} & \text { if } \chi \leq 1 \\ \chi \theta^{*}(\chi, \tau) & \text { if } \chi>1\end{cases}
$$

where $\Omega \equiv \theta^{*}(\chi, \tau)-s^{*}(\chi, \tau)+\varepsilon$. According to equation (19), $\Omega$ can be rearranged to $\Omega=2 \varepsilon\left(\frac{u(1+\gamma-\tau)-u(1-\tau)}{u(1+\gamma-\tau)-u(\chi-\tau)}\right) \forall \chi \leq 1$. Observe that $0<\Omega \leq 2 \varepsilon$, establishing $0 \leq q(\chi, \tau) \leq \chi$ $\forall \chi \in[0,1+\gamma]$. Thus, since $q(\chi, \tau)$ is continuous in $\tau$, there exists at least one value of $\tau$ solving $\tau=q(\chi, \tau)$, and a sufficient condition for single crossing as $\tau$ is raised from 0 to $\chi$ is $\frac{\partial q(\chi, \tau)}{\partial \tau}<1 \forall \tau \in[0, \chi]$. The derivative $\frac{\partial q(\chi, \tau)}{\partial \tau}$ is

$$
\frac{\partial q(\chi, \tau)}{\partial \tau}= \begin{cases}\frac{\chi \Omega}{2 \varepsilon} \frac{\partial \Omega}{\partial \tau} & \text { if } \chi \leq 1 \\ 0 & \text { if } \chi>1\end{cases}
$$

where $\frac{\partial \Omega}{\partial \tau}=2 \varepsilon \frac{-[u(1+\gamma-\tau)-u(\chi-\tau)]\left[u^{\prime}(1+\gamma-\tau)-u^{\prime}(1-\tau)\right]+[u(1+\gamma-\tau)-u(1-\tau)]\left[u^{\prime}(1+\gamma-\tau)-u^{\prime}(\chi-\tau)\right]}{[u(1+\gamma-\tau)-u(\chi-\tau)]^{2}}<$ $\frac{-2 \varepsilon[u(1-\tau)-u(\chi-\tau)]\left[u^{\prime}(1+\gamma-\tau)-u^{\prime}(\chi-\tau)\right]}{[u(1+\gamma-\tau)-u(\chi-\tau)]^{2}}<\frac{-2 \varepsilon\left[u^{\prime}(1+\gamma-\tau)-u^{\prime}(\chi-\tau)\right]}{u(1+\gamma-\tau)-u(\chi-\tau)}$. Because $\Omega \leq 2 \varepsilon$, this implies that $\forall \chi \leq 1$, a sufficient condition for $\frac{\partial q(\chi, \tau)}{\partial \tau}<1$ is $\frac{-\chi\left[u^{\prime}(1+\gamma-\tau)-u^{\prime}(\chi-\tau)\right]}{u(1+\gamma-\tau)-u(\chi-\tau)} \leq \frac{1}{2 \varepsilon}$, which in turn must hold if $\frac{-\chi u^{\prime \prime}(C)}{u^{\prime}(C)} \leq \frac{1}{2 \varepsilon} \forall C \in[\chi, 1]$. This proves that $\forall \chi \in[0,1+\gamma]$, there is a unique $\tau$ satisfying $\tau=q(\chi, \tau)$, as claimed. 
Hence, by virtue of the preceding lemmas, the unique equilibrium is characterized by the threshold $s^{*}(\chi) \equiv s^{*}\left(\chi, \tau^{*}(\chi)\right)$ of small depositors' signals, by the threshold $\theta^{*}(\chi) \equiv$ $\theta^{*}\left(\chi, \tau^{*}(\chi)\right)$ of bank failure and of the large lender's signal, by the risk level $v^{*}(\chi) \equiv$ $v^{*}\left(\chi, \tau^{*}(\chi)\right)$, and by the premium $\tau^{*}(\chi)$. This proves Proposition 1. Q.E.D.

\section{A.2 Proposition 2}

In a first step, by equation (24), totally differentiating $\tau^{*}(\chi)=q\left(\chi, \tau^{*}(\chi)\right)$ with respect to $\chi$ and defining $\Omega$ as in Appendix A.1 results in

$$
\frac{d \tau^{*}(\chi)}{d \chi}=\left(\frac{\Omega^{2}}{4 \varepsilon}+\frac{\chi \Omega}{2 \varepsilon} \frac{\partial \Omega}{\partial \chi}\right)\left(1-\frac{\chi \Omega}{2 \varepsilon} \frac{\partial \Omega}{\partial \tau}\right)^{-1}
$$

$\forall \chi \leq 1$. Notice that $\frac{\partial \Omega}{\partial \chi}=\frac{2 \varepsilon u^{\prime}(\chi-\tau)[u(1+\gamma-\tau)-u(1-\tau)]}{[u(1+\gamma-\tau)-u(\chi-\tau)]^{2}}>0$ and, from the proof of Lemma 3 , that $\frac{\chi \Omega}{2 \varepsilon} \frac{\partial \Omega}{\partial \tau}<1$, such that $\frac{d \tau^{*}(\chi)}{d \chi}>0$ follows immediately from $(26)$ if $\chi \leq 1$. If $\chi>1$, equations (20) and $(22)$ show that $\theta^{*}(\chi, \tau)$ depends neither on $\chi$ nor on $\tau$, which according to equation (24) again implies $\frac{d \tau^{*}(\chi)}{d \chi}>0$. This proves result (iv) of the proposition.

Second, recall from equation (22) that $\frac{d v^{*}(\chi)}{d \chi}=0$ whenever $\chi>1$ or if $v^{*}(\chi)$ is bounded by 0 or by 1 . In all other cases, invoking $v^{*}(\chi) \equiv v^{*}\left(\chi, \tau^{*}(\chi)\right)$ and $\frac{u(1-\tau)-u(\chi-\tau)}{u(1+\gamma-\tau)-u(\chi-\tau)}=\frac{1-\Omega}{2 \varepsilon}$, equation (22) involves $\frac{d v^{*}(\chi)}{d \chi}=\frac{(1-\alpha) \xi}{4 \kappa \varepsilon} \frac{d \Omega}{d \chi}$. The messy part of the proof is to derive the sign of $\frac{d \Omega}{d \chi}$. Total differentiation of $\Omega$ with respect to $\chi$ yields

$$
\frac{d \Omega}{d \chi}=\frac{\Omega u^{\prime}(\chi-\tau)}{u(1+\gamma-\tau)-u(\chi-\tau)}+\frac{2 \varepsilon \Psi\left(\frac{\Omega^{2}}{4 \varepsilon}+\frac{\chi \Omega}{2 \varepsilon} \frac{\partial \Omega}{\partial \chi}\right)}{[u(1+\gamma-\tau)-u(\chi-\tau)]^{2}\left(1-\frac{\chi \Omega}{2 \varepsilon} \frac{\partial \Omega}{\partial \tau}\right)},
$$

where

$$
\begin{aligned}
\Psi & =u^{\prime}(1-\tau)[u(1+\gamma-\tau)-u(\chi-\tau)] \\
& -u^{\prime}(\chi-\tau)[u(1+\gamma-\tau)-u(1-\chi)] \\
& -u^{\prime}(1+\gamma-\tau)[u(1-\tau)-u(\chi-\tau)] .
\end{aligned}
$$

After some algebra, the derivative in (27) can be transformed to

$$
\begin{aligned}
\frac{d \Omega}{d \chi} & =\Omega \frac{u^{\prime}(\chi-\tau)[u(1+\gamma-\tau)-u(\chi-\tau)]+\Psi \varepsilon[u(1+\gamma-\tau)-u(1-\tau)]}{[u(1+\gamma-\tau)-u(\chi-\tau)]^{3}-2 \varepsilon \chi \Psi[u(1+\gamma-\tau)-u(1-\tau)]} \\
& =\frac{\Omega\left[u^{\prime}(\chi-\tau) A+\varepsilon B\right]}{[u(1+\gamma-\tau)-u(\chi-\tau)]^{3}-2 \varepsilon \chi \Psi[u(1+\gamma-\tau)-u(1-\tau)]},
\end{aligned}
$$


where the terms $A$ and $B$ are

$$
\begin{aligned}
& A=u(1-\tau)-u(\chi-\tau)+(1-\varepsilon)[u(1+\gamma-\tau)-u(1-\tau)] \quad \text { and } \\
& B=u^{\prime}(1-\tau)[u(1+\gamma-\tau)-u(1-\tau)]+\left[u^{\prime}(1-\tau)-u^{\prime}(1+\gamma-\tau)\right][u(1-\tau)-u(\chi-\tau)] .
\end{aligned}
$$

Note that the numerator in (29) is positive for any increasing and weakly concave function $u(\cdot)$ and that the denominator also exceeds 0 if $\Psi \leq 0$, such that $\frac{d \Omega}{d \chi}>0$ evolves in this case. Conversely, if $\Psi>0$, in which case $\frac{\partial \Omega}{\partial \tau}>0$ must hold, $\frac{d \Omega}{d \chi}=\frac{\partial \Omega}{\partial \chi}+\frac{\partial \Omega}{\partial \tau^{*}} \frac{d \tau^{*}}{d \chi}>0$ directly follows from the above results $\frac{d \tau^{*}}{d \chi}>0$ and $\frac{\partial \Omega}{\partial \chi}>0$. Thus we have shown that $\frac{d \Omega}{d \chi}>0$. This proves that $\frac{d v^{*}(\chi)}{d \chi} \geq 0$ as claimed in part (v) of the proposition.

In a third step, $\frac{d \Omega}{d \chi}>0, \frac{d \theta^{*}(\chi)}{d \chi}=\frac{-(1-\alpha) \xi}{4 \varepsilon} \frac{d \Omega}{d \chi}$ and $\frac{d s^{*}(\chi)}{d \chi}=\frac{d \theta^{*}(\chi)}{d \chi}-\frac{d \Omega}{d \chi}$ imply $\frac{d s^{*}(\chi)}{d \chi}<$ $\frac{d \theta^{*}(\chi)}{d \chi}<0$ as stated in part (i) of Proposition 2. The remaining parts (ii) and (iii) are immediate corollaries of result (i) and of equations (15) and (14). Q.E.D.

\section{A.3 Proposition 3}

If $u(C)=C$ and according to equations (19), (20), and (24), then the equilibrium values $\theta^{*}(\chi, v), s^{*}(\chi, v)$, and $\tau^{*}(\chi, v)$ conditional on an exogenous $v$ do not depend on $\tau$ and simplify to

$$
\begin{aligned}
& \theta^{*}(\chi, v)=\left\{\begin{array}{ll}
\eta+\kappa v+\frac{(1-\chi)(1-\alpha) \xi}{(1+\gamma-\chi)} & \text { if } \chi \leq 1 \\
\eta+\kappa v & \text { if } \chi>1
\end{array},\right. \\
& s^{*}(\chi, v)=\left\{\begin{array}{ll}
\eta+\kappa v+\frac{(1-\chi)(1-\alpha) \xi}{(1+\gamma-\chi)}+\frac{(1-\gamma-\chi) \varepsilon}{(1+\gamma-\chi)} & \text { if } \chi \leq 1 \\
-\varepsilon & \text { if } \chi>1
\end{array},\right. \text { and } \\
& \tau^{*}(\chi, v)=\left\{\begin{array}{ll}
\frac{\gamma^{2} \varepsilon \chi}{(1+\gamma-\chi)^{2}} & \text { if } \chi \leq 1 \\
(\eta+\kappa v) \chi & \text { if } \chi>1
\end{array} .\right.
\end{aligned}
$$

By equation (22), the bank manager's optimal choice of $v$ can be computed as

$$
v^{*}(\chi)=\left\{\begin{array}{ll}
\max \left[0, \min \left[1, \frac{1-\eta-\beta \kappa(1+\gamma)}{2 \kappa}-\frac{(1-\alpha) \xi(1-\chi)}{2 \kappa(1+\gamma-\chi)}\right]\right] & \text { if } \chi \leq 1 \\
\max \left[0, \min \left[1, \frac{1-\eta-\beta \kappa(1+\gamma)}{2 \kappa}\right]\right] & \text { if } \chi>1
\end{array} .\right.
$$

Plugging $v^{*}(\chi)$ into the above solutions then yields $\theta^{*}(\chi), s^{*}(\chi)$, and $\tau^{*}(\chi)$ with an endogenous risk level $v^{*}(\chi)$. Observe from equations (30) to (32) that there is a sudden increase 
in $\tau^{*}$ if $\chi$ exceeds 1 , because no creditor withdraws at $t=1$ in this case. Further raising $\chi$ above 1 does not affect any threshold but increases taxes, such that $\forall \chi \in(1,1+\gamma]$, welfare even decreases with $\chi$ if $c>0$. Hence, no $\chi>1$ can constitute an optimum, and this fact allows us to restrict attention to $\chi \in[0,1]$.

After plugging the expressions in (30) to (32) into equations (8) to (14) and computing $W(\chi)$ as given by (6), differentiating $W(\chi)$ and solving the first-order condition for $\chi$ yields a unique solution $\chi_{I}^{*}$ if $v^{*}(\chi) \in(0,1)$ or $\chi_{I I}^{*}$ if $v^{*}(\chi)$ is bounded by 0 or 1 . Since it can be shown that $\left.\frac{d^{2} W(\chi)}{d \chi^{2}}\right|_{\chi=\chi_{I}^{*}}<0$ and $\left.\frac{d^{2} W(\chi)}{d \chi^{2}}\right|_{\chi=\chi_{I I}^{*}}<0, \chi_{I}^{*}$ or $\chi_{I I}^{*}$ is indeed an optimum provided these solutions are within $[0,1]$. Now, define by $\underline{\beta}$ [by $\bar{\beta}]$ the critical value of $\beta$ that solves $v^{*}=1\left[v^{*}=0\right]$. Likewise, let $\underline{\xi_{I}}$ and $\overline{\xi_{I}}[\underline{\xi}$ and $\bar{\xi}]$ be the values of $\xi$ solving $\chi_{I}^{*}=0$ and $\chi_{I}^{*}=1\left[\chi_{I I}^{*}=0\right.$ and $\left.\chi_{I I}^{*}=1\right]$. Since $\underline{\xi_{I}}=2 \underline{\xi}$ and $\overline{\xi_{I}}=2 \bar{\xi}$, the optimal $\chi$ can be summarized as in Proposition 3, while $\frac{d v^{*}}{d \beta}<0$ and $\frac{d \chi^{*}}{d \xi}>0$ ensure $\bar{\beta}>\underline{\beta}$ and $\bar{\xi}>\underline{\xi}$.

To prove part (ii) of the proposition, notice that if $v$ is exogenous, $\frac{d W(\chi)}{d \chi}$ does not depend on $v$, and the optimal coverage is again $\chi_{I I}^{*}$ unless it is 0 or 1 . Because $\chi_{I I}^{*}>\chi_{I}^{*}$, this implies $\chi^{*} \geq \chi_{v}^{*}$ as claimed. Q.E.D.

\section{A.4 Proposition 4}

In the presence of contagion, the objective function of the insurer can be written as

$$
W_{C}(\chi)=\left(w_{1}-1+N-K\right) W(\chi \mid \eta)+K\left[\theta^{*}(\chi) W(\chi \mid \bar{\eta})+\left(1-\theta^{*}(\chi)\right) W(\chi \mid \underline{\eta})\right]
$$

where $W(\chi)$ is given by $(6) . \chi_{C}^{*}$ is the value of $\chi$ solving the first-order condition

$$
\frac{d W(\chi)}{d \chi} \frac{\left(w_{1}-1\right)+(N-K)}{K}=\frac{d \theta^{*}(\chi)}{d \chi}(W(\chi \mid \underline{\eta})-W(\chi \mid \bar{\eta})) .
$$

if it is an interior solution. Since $W(\chi \mid \underline{\eta})-W(\chi \mid \bar{\eta})>0$ and $\frac{d \theta^{*}(\chi)}{d \chi}<0$, the right-hand side of (35) is negative for any $\chi$. Invoking that $\left.\frac{d^{2} W(\chi)}{d \chi^{2}}\right|_{\chi=\chi^{*}}<0$ and that $\left.\frac{d W(\chi)}{d \chi}\right|_{\chi=\chi^{*}}=0$ if $\chi^{*} \in[0,1]$, this implies $\chi_{C}^{*}>\chi^{*}$ if $\chi_{C}^{*} \in[0,1]{ }^{19}$ A completely analogous argument establishes that the optimal $\chi_{1}^{*}$, which is the value of $\chi_{1}$ solving

$$
\frac{d W\left(\chi_{1}\right)}{d \chi_{1}} \frac{w_{1}}{K}=\frac{d \theta^{*}\left(\chi_{1}\right)}{d \chi_{1}}\left(W\left(\chi^{*} \mid \underline{\eta}\right)-W\left(\chi^{*} \mid \bar{\eta}\right)\right)
$$

\footnotetext{
${ }^{19}$ Computations are available from the author on request.
} 
if it is an interior solution, must also exceed $\chi^{*}$. Now recall that $\chi^{*}$ does not depend on $\eta$, from which follows $\chi_{i}^{*}=\chi^{*}$ for $i=2, \ldots, N$. This means that raising the coverage amount $\chi_{i}$ of any individual bank $i=1, \ldots, N$ above $\chi^{*}$ is detrimental to creditors of that particular bank. The only reason for setting $\chi_{1}^{*}>\chi^{*}$ in case of bank 1 is that depositors of the $K$ susceptible banks benefit from reduced failures of bank 1. Clearly, this also implies $\frac{\chi_{1}^{*}}{d w_{1}}<0$ and $\frac{\chi_{i}^{*}}{d w_{1}}=0 \forall i \neq 1$. The same logic also establishes that if the same coverage amount applies for all banks, the optimal $\chi_{C}^{*}$ is increasing in $\frac{K}{N}$ and decreasing in $w_{1}$. Q.E.D.

\section{A.5 Proposition 5}

To obtain a sketch of the proof, notice that in case of coinsurance, risk-neutral creditors continue to withdraw either 0 or 1 , such that the unique equilibrium and the optimal $\widehat{\chi}$ are essentially equivalent to the results derived in Propositions 1 and 3. There is one subtle difference though. By continuity, the additional assumption that depositors never withdraw fully insured claims must also hold under coinsurance if $\widehat{\chi}=1$, and the sudden decrease in $s^{*}$ and increase in $\tau^{*}$, which are familiar from equations (31) and (32), do not occur if the coverage amount is raised above 1 , but already occur if $\widehat{\chi}$ meets 1 . Hence the optimal $\chi^{*}$ must be smaller than 1, although in some cases by an arbitrarily small amount.

In case of a cap $\bar{\chi}$, the equilibrium can again be derived as in Appendix A.1, with the only difference being the introduction of partial switching strategies according to which depositors withdraw $1-\bar{\chi}$ if their signal is $s_{i} \leq s$ and 0 otherwise. Thus, given $\theta$, an amount

$$
l(s, \theta)= \begin{cases}0 & \text { if } s<\theta-\varepsilon \\ (1-\bar{\chi})[s-(\theta-\varepsilon)] / 2 \varepsilon & \text { if } \theta-\varepsilon \leq s \leq \theta+\varepsilon \\ 1-\bar{\chi} & \text { if } s>\theta+\varepsilon\end{cases}
$$

is withdrawn at $t=1$, and there is a critical threshold $\widetilde{\theta}(s, \bar{\chi})=\frac{2 \varepsilon(\eta+\kappa v)+\xi(1-\bar{\chi})(s+\varepsilon)}{2 \varepsilon+\xi(1-\bar{\chi})}$ of $\theta$ above which the bank succeeds. The expected utility differential between rolling over and partially withdrawing, conditional on $s_{i}=s$ and on the aggregate switching point $s$, is $H(s, \bar{\chi})=P\left(\theta>\widetilde{\theta}(s, \bar{\chi}) \mid s_{i}=s\right)(1-\bar{\chi}) \gamma-P\left(\theta \leq \tilde{\theta}(s, \bar{\chi}) \mid s_{i}=s\right)(1-\bar{\chi})$. By complete 
analogy to Lemma 1, it can then be shown that there is a unique value

$$
\bar{s}^{*}(\bar{\chi}, v)= \begin{cases}\eta+\kappa v+\left(\frac{1-\bar{\chi}}{1+\gamma}\right) \xi+\left(\frac{1-\gamma}{1+\gamma}\right) \varepsilon & \text { if } \chi \leq 1 \\ -\varepsilon & \text { if } \chi>1\end{cases}
$$

of $s$ solving $H(s, \bar{\chi})=0$, which implies a unique fundamental threshold

$$
\bar{\theta}^{*}(\bar{\chi}, v)= \begin{cases}\eta+\kappa v+\left(\frac{1-\bar{\chi}}{1+\gamma}\right) \xi & \text { if } \chi \leq 1 \\ \eta+\kappa v & \text { if } \chi>1\end{cases}
$$

in a cap regime. The equilibrium choice of $v$ can be derived as in Appendix A.1 and can be substituted into the above thresholds $\bar{s}^{*}(\bar{\chi}, v)$ and $\bar{\theta}^{*}(\bar{\chi}, v)$, whereas the equilibrium premium is $\bar{\tau}^{*}(\bar{\chi})=\bar{\chi} \bar{\theta}^{*}(\bar{\chi})$. Again, this equilibrium is unique. ${ }^{20}$

Next, denote welfare under a cap regime by $\bar{W}(\bar{\chi})$, which, $\forall \bar{\chi}<1$, is computed as

$$
\begin{aligned}
\bar{W}(\bar{\chi})= & P\left[s_{i}>\bar{s}^{*}(\bar{\chi})\right]\left(\bar{\chi} P\left[\theta \leq \bar{\theta}^{*}(\bar{\chi}) \mid s_{i}>\bar{s}^{*}(\bar{\chi})\right]+(1+\gamma) P\left[\theta>\bar{\theta}^{*}(\bar{\chi}) \mid s_{i}>\bar{s}^{*}(\bar{\chi})\right]\right) \\
& +P\left[s_{i} \leq \bar{s}^{*}(\bar{\chi})\right]\left(1+\gamma \bar{\chi} P\left[\theta>\bar{\theta}^{*} \mid s_{i} \leq \bar{s}^{*}(\bar{\chi})\right]\right)-(1+c) \bar{\tau}^{*}(\bar{\chi}) .
\end{aligned}
$$

Unlike in the case of proportional insurance, some further algebra reveals that $\frac{d^{2} \bar{W}}{d \bar{\chi}^{2}}=$ $\frac{2(1+c) \xi}{(1+\gamma)}>0$ for any $\bar{\chi} \in[0,1]$ and $\frac{d \bar{W}}{d \bar{\chi}}<0 \forall \bar{\chi}>1$, which leaves $\bar{\chi} \in\{0,1\}$ as the only subset of candidates for an optimal cap. ${ }^{21}$ Now the proof of Proposition 5 draws on a simple logic: Since the optimal $\bar{\chi}$ is either 1 or 0 , the same result can also be achieved by setting $\widehat{\chi}$ to 1 or 0 . However, $\widehat{\chi}=1$ is never the best choice in case of coinsurance. So the latter strictly dominates a system with caps unless the optimal $\widehat{\chi}$ is 0 . Q.E.D.

\section{A.6 Proposition 6}

Since there is no strategic uncertainty under either a LolR with public disclosure of $\theta$ or a bailout policy, the failure threshold boils down to $\theta^{*}=\eta+\kappa v$. The implied risk level $v^{*}=\max \left[\min \left[\frac{1-\eta-\beta \kappa(1+\gamma)}{2 \kappa}, 1\right], 0\right]$ weakly exceeds $v^{*}(\chi)$ without LolR or bailouts (see Appendix A.1), as claimed in Proposition 6 (iii). The resulting $\theta^{*}=\eta+\frac{1-\eta-\beta \kappa(1+\gamma)}{2}$ is lower than without LolR or bailouts. Thus, the net effect of restoring coordination is positive.

\footnotetext{
${ }^{20}$ See Frankel et al. (2003) for a proof with strategic complementarities and continuous actions.

${ }^{21}$ More detailed derivations are available from the author on request.
} 
In a next step, notice that the LolR with public disclosure of $\theta$ also fully prevents type I and type II errors by depositors $\forall \chi \leq 1$, ensuring that $\tau^{*}=0$ and further improving welfare. If $\chi>1$, depositors never withdraw, irrespective of whether there is a LolR. This implies that $\frac{d W^{\text {lolr }}(\chi)}{d \chi}=0 \forall \chi<1, \frac{d W^{\text {lolr }}(\chi)}{d \chi}<0 \forall \chi>1$ and $W^{\text {lolr }}(0)>W\left(\chi^{*}\right)$.

Under a bailout policy, no creditor withdraws at $t=1$ even if $\chi \leq 1$, from which follows $\frac{d W^{b}(\chi)}{d \chi}=0 \forall \chi$. By virtue of Proposition 3, no $\chi>1$ can be an optimal level of coverage in the absence of bailouts. Moreover, observe that offering any $\chi>1$ to the large lender further decreases welfare for the same reasons as in the case of small depositors. Taken together, this implies $W\left(\chi^{*}\right)>W^{b}(0)$ and completes the proof of Proposition 6 . 